\title{
Prognostic impact of epidermal growth factor receptor (EGFR) expression on loco-regional recurrence after preoperative radiotherapy in rectal cancer
}

\author{
David Azria*1,2, Frederic Bibeau ${ }^{3}$, Nicolas Barbier ${ }^{1}$, Abderrahim Zouhair ${ }^{1,4}$, \\ Claire Lemanski ${ }^{1}$, Philippe Rouanet ${ }^{5}$, Marc Ychou ${ }^{6,2}$, Pierre Senesse ${ }^{6}$, \\ Mahmut Ozsahin ${ }^{4}$, André Pèlegrin ${ }^{2}$, Jean-Bernard Dubois ${ }^{1}$ and \\ Simon Thèzenas ${ }^{7}$
}

\begin{abstract}
Address: ${ }^{1}$ Department of Radiation Oncology, Val d'Aurelle Cancer Institute, Montpellier, France, ${ }^{2}$ INSERM, EMI 0227, Val d'Aurelle Cancer Institute, Montpellier, France, ${ }^{3}$ Department of Pathology, Val d'Aurelle Cancer Institute, Montpellier, France, ${ }^{4}$ Department of Radiation Oncology, Centre Hospitalier Universitaire Vaudois, Lausanne, Switzerland, ${ }^{5}$ Department of Surgical Oncology, Val d'Aurelle Cancer Institute, Montpellier, France, ${ }^{6}$ Department of Medical and Digestive Oncology, Val d'Aurelle Cancer Institute, Montpellier, France and ${ }^{7}$ Biostatistics Unit, Val d'Aurelle Cancer Institute, Montpellier, France

Email: David Azria* - azria@valdorel.fnclcc.fr; Frederic Bibeau - fbibeau@valdorel.fnclcc.fr; Nicolas Barbier - niicccoooo@wanadoo.fr; Abderrahim Zouhair - Abderrahim.Zouhair@chuv.hospvd.ch; Claire Lemanski - clemanski@valdorel.fnclcc.fr;

Philippe Rouanet - prouanet@valdorel.fnclcc.fr; Marc Ychou - mychou@valdorel.fnclcc.fr; Pierre Senesse - psenesse@valdorel.fnclcc.fr; Mahmut Ozsahin - esat-mahmut.ozsahin@chuv.hospvd.ch; André Pèlegrin - apelegrin@valdorel.fnclcc.fr; JeanBernard Dubois - jbdubois@valdorel.fnclcc.fr; Simon Thèzenas - sthezenas@valdorel.fnclcc.fr

* Corresponding author
\end{abstract}

Published: 20 June 2005

BMC Cancer 2005, 5:62 doi:10.1 186/147/-2407-5-62
Received: 17 December 2004

Accepted: 20 June 2005

This article is available from: http://www.biomedcentral.com/I47I-2407/5/62

(c) 2005 Azria et al; licensee BioMed Central Ltd.

This is an Open Access article distributed under the terms of the Creative Commons Attribution License (http://creativecommons.org/licenses/by/2.0), which permits unrestricted use, distribution, and reproduction in any medium, provided the original work is properly cited.

\begin{abstract}
Background: Epidermal growth factor receptor (EGFR) represents a major target for current radiosensitizing strategies. We wished to ascertain whether a correlation exists between the expression of EGFR and treatment outcome in a group of patients with rectal adenocarcinoma who had undergone preoperative radiotherapy (RT).

Methods: Within a six-year period, 138 patients underwent preoperative radiotherapy and curative surgery for rectal cancer (UICC stages II-III) at our institute. Among them, 77 pretherapeutic tumor biopsies were available for semi-quantitative immunohistochemical investigation evaluating the intensity and the number (extent) of tumor stained cells. Statistical analyses included Cox regression for calculating risk ratios of survival endpoints and logistic regression for determining odds ratios for the development of loco-regional recurrences.

Results: Median age was 64 years (range: $30-88$ ). Initial staging showed $75 \%$ and $25 \%$ stage II and III tumors, respectively. RT consisted of 44-Gy pelvic irradiation in 2-Gy fractions using I8-MV photons. In 25 very low-rectal-cancer patients the primary tumor received a boost dose of up to 16 Gy for a sphincter-preservation approach. Concomitant chemotherapy was used in $17 \%$ of the cases. All patients underwent complete total mesorectal resection. Positive staining (EGFR+) was observed in 43 patients (56\%). Median follow-up was 36 months (range: 6-86). Locoregional recurrence rates were 7 and $20 \%$ for EGFR extent inferior and superior to $25 \%$, respectively. The
\end{abstract}


corresponding locoregional recurrence-free survival rate at two years was $94 \%$ ( $95 \%$ confidence interval, $\mathrm{Cl}, 92-98 \%)$ and $84 \%(\mathrm{Cl} 95 \%, 58-95 \%)$, respectively $(\mathrm{P}=0.06)$. Multivariate analyses showed a significant correlation between the rate of loco-regional recurrence and three parameters: EGFR extent superior to $25 \%$ (hazard ratio $=7.18, \mathrm{Cl} 95 \%, \mathrm{I} .17-46, \mathrm{P}=0.037$ ), rectal resection with microscopic residue (hazard ratio $=6.92, \mathrm{Cl} 95 \%, \mathrm{I} .18-40.4 \mathrm{I}, \mathrm{P}=0.032$ ), and a total dose of $44 \mathrm{~Gy}$ (hazard ratio $=5.78, \mathrm{Cl} 95 \%, 1.04-32.05, \mathrm{P}=0.045$ ).

Conclusion: EGFR expression impacts on loco-regional recurrence. Knowledge of expression of EGFR in rectal cancer could contribute to the identification of patients with an increased risk of recurrences, and to the prediction of prognosis.

\section{Background}

In patients with rectal carcinoma, pelvic recurrence is a major source of morbidity and mortality. Despite improvements in surgical approaches, local recurrence may occur in up to $30 \%$ of patients treated with surgery including total mesorectal excision [1]. Since 2001, the Dutch Colorectal Cancer Group Trial [2] has confirmed that a short course of radiotherapy (RT) reduced the rate of pelvic recurrence at 3 years, from $10.1 \%$ to $3.4 \%$. In addition, a meta-analysis of 19 randomized trials including preoperative RT tends to show that it provides a gain of three percent at 5 years in overall survival [3]. However despite these recent intensive clinical investigations, there is still a need to develop novel strategies in the management of patients with locally advanced rectal cancer.

Advances in the understanding of the molecular biology of rectal cancer have opened many new research directions. Increasing effort has been directed towards developing molecular targeted therapies or searching for molecular markers that are useful either in predicting treatment outcome or in selecting patients for specific molecular targeted therapies, based on particular tumor characteristics. None of the recent studies has identified convincing data to warrant routine clinical application of any marker such as p53 [4,5], or apoptosis regulators [6].

To date, no data have become available that shed light on the impact of EGFR expression on local and distant relapse in patients treated with preoperative RT and extensive local surgery i.e. abdominoperineal excision or low anterior resection with total mesorectal excision. We present here the prognostic impact of EGFR expression on locoregional recurrence in 77 patients treated with preoperative RT at our institute.

\section{Methods}

\section{Patient selection and pretreatment evaluation}

Within a six-year period (April 1996 and September 2002), 138 patients underwent preoperative radiotherapy and curative surgery for rectal cancer (UICC stages II-III) at the Val d'Aurelle Cancer Institute of Montpellier, France. A carcinoma was considered a primary rectal car- cinoma if it was located in the lower third ( $<6 \mathrm{~cm}$ from the anal verge), middle third $(6-12 \mathrm{~cm})$, and upper third of the rectum (above $12 \mathrm{~cm}$ ). Pretherapy biopsies were available for analysis in 77 patients and were evaluable for the statistical results. Diagnostic and distant disease extension studies consisted of colorectal endoscopy with biopsies, rectal ultrasonography (uT), presurgical carcinoembryonic antigen (CEA) value, abdominal and pelvic computed tomography (CT) scans, chest X-ray or CT-scan and routine laboratory studies. All patients were metastasisfree at diagnosis.

\section{EGFR immunohistochemical assay (IHC)}

IHC of the tumor biopsies was performed by using the Dako autostainer (DakoCytomation, Glostrup, Denmark) and the EGFR Pharm Dx kit ${ }^{\circledR}$ K 1494 (Dako Cytomation, Glostrup, Denmark), according to the manufacturer's instructions with the reagents supplied with the kit. Briefly, sections of $3 \mu \mathrm{m}$ were mounted on silanized slides and allowed to dry overnight at $37^{\circ} \mathrm{C}$. After deparaffinization and rehydratation, slides were incubated with $3 \%$ hydrogen peroxide solution for $5 \mathrm{~min}$. After a washing procedure with the supplied buffer, tissue sections were covered for $5 \mathrm{~min}$ with protein $\mathrm{K}$ solution. The slides were then incubated for $30 \mathrm{~min}$ with the primary mouse antiEGFR MAb (clone 2-18C9), which binds to a formalinresistant epitope near the ligand-binding site on the extra cellular domain of the EGFR and recognizes both wild type and mutant type (vIII). After two rinses in buffer, the slides were incubated with the detection system for 30 min (labeled polymer-HRP). Tissue staining was visualized with a DAB substrate chromogen solution. Slides were counterstained with hematoxylin, dehydrated, and mounted. Negative control sections were processed without the primary antibody but with an irrelevant murine IgG1 supplied with the kit. Negative and positive control cell slides provided with the kit EGFR Pharm Dx ${ }^{\circledR}$ were also used, to ensure that each assay run was performed appropriately and according to protocol specifications. Furthermore, perineurium was considered as a positive internal control on tumor slides. EGFR assessment was realized according to the EGFR Pharm Dx ${ }^{\circledast}$ scoring guidelines. Results were reported as positive when a complete 

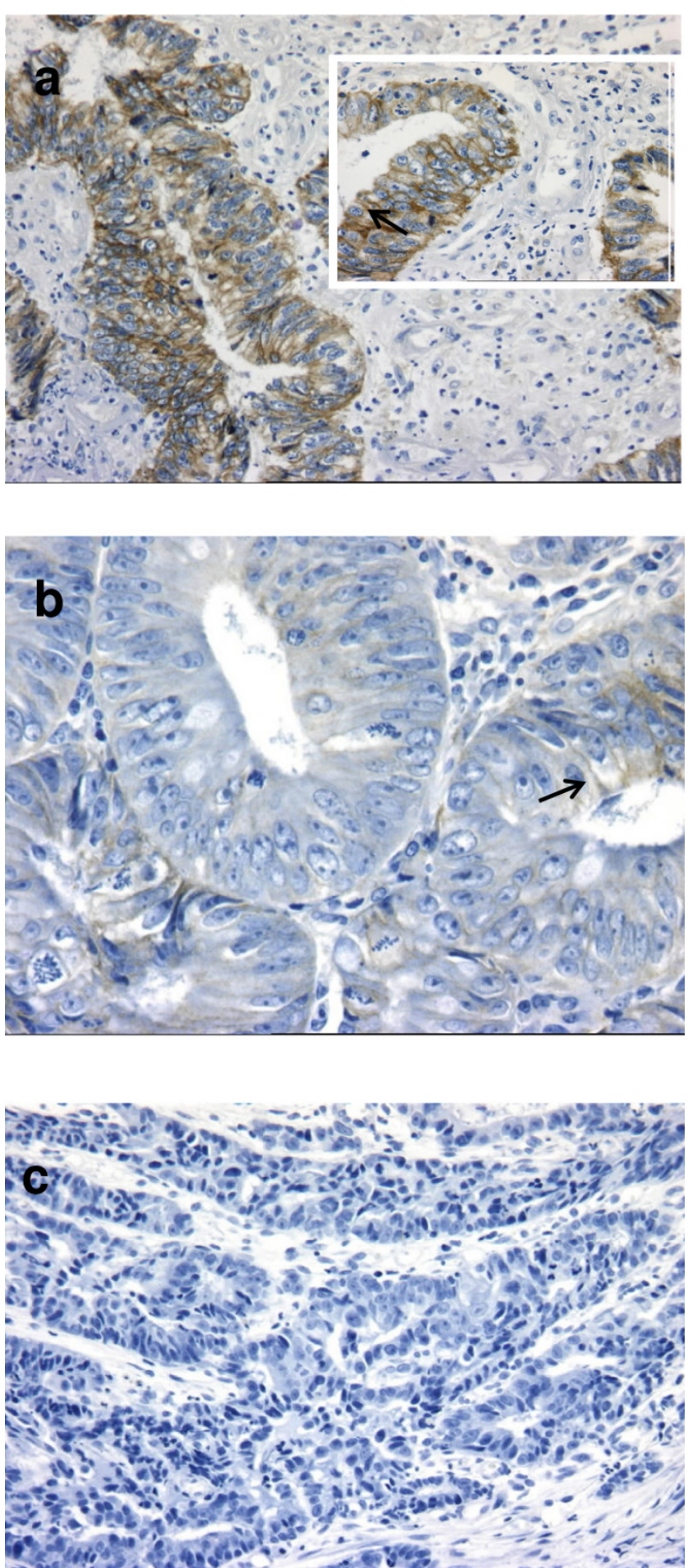

Figure I

Patterns of EGFR expression. a) Case with an extent positivity $\geq 25 \%$ with strong membrane staining of tumor cells. Insert and arrow: note the membranous positivity pattern (immunoperoxydase $\times 100$ and $\times 400$ ). b) Case with an extent positivity $<25 \%$ with weak membrane staining of some tumor cells (arrow) (immunoperoxydase $\times 400$ ). c) Case with negative staining (immunoperoxydase $\times 200$ ). or incomplete circumferential membrane staining was observed in at least $1 \%$ of the tumor cells. Staining was defined as any IHC staining of tumor cell membranes above background level, i.e., weak, moderate, or strong. Absence of or cytoplasm staining was reported as negative. In addition to these standardized criteria, the pathologist performed a semi-quantitative evaluation reporting both intensity and percentage (extent) of tumor cells staining blinded to clinical data (Figure 1).

\section{Preoperative radiation therapy (RT) and surgical modalities}

Patients were treated in supine position with a 3-field (posterior and two opposed laterals) isocentric technique using 18-MV photon beams daily, five times a week. The daily dose at the isocenter was $2 \mathrm{~Gy}$; the total dose to the entire pelvis was $44 \mathrm{~Gy}$. In 25 very low-rectal-cancer patients, primary tumor received a boost dose of up to 16 Gy for a sphincter-preservation approach. Clinical target volume (CTV) included the tumor and the entire rectum, the anterior wall of the sacrum and the posterior wall of the prostate or vagina, and the following lymph nodes: perirectal, presacral, hypogastric, obturator, and low common iliac nodes. The planning target volume (PTV) included the clinical target volume plus a $1-1.5-\mathrm{cm}$ margin. The superior margin was the L5-S1 interspace in most patients; in some patients with tumors very close to the anus, however, the cranial margin was placed somewhat lower, but always at least $5 \mathrm{~cm}$ above the tumor area. The lateral margins were $1 \mathrm{~cm}$ outside the bony margins of the true pelvis. The posterior margin was placed just posterior to the sacrum. The anterior margin was dependent on the anterior extension (gross tumor volume, GTV) of the primary tumor. Individually shaped blocks were used to shield normal tissues. The boost volume covered the primary tumor plus a $1.5-\mathrm{cm}$ margin using a 3 -field (posterior and oblique) technique. Standard or CT-scan simulation was used. With the CT-scan simulator (Picker PQ 2000 + ACQSIM), GTV, CTV, and PTV were determined as defined above, the treated volume and the irradiated volume according to the ICRU report 50 [7]. Fields were marked during initial CT-scan simulation after the ICRU reference was calculated.

Thirteen patients $(17 \%)$ received concomitant chemotherapy. In eight patients, the chemotherapy regimen consisted of continuous infusion of $200-250 \mathrm{mg} / \mathrm{m}^{2} /$ day of 5-fluorouracil (5-FU) alone beginning on the first day of radiation therapy, five days a week for 5 weeks. Oxaliplatin $\left(40 \mathrm{mg} / \mathrm{m}^{2} /\right.$ day at days $1,8,15,22$, and 29$)$ and leucovorin $\left(100 \mathrm{mg} / \mathrm{m}^{2} /\right.$ day at days $1-2,15-16$, and 29-30) were added at the same protocol of 5-FU for two and three patients, respectively. 
Median time between the last day of radiotherapy and surgery was 41 days (range: 13-97). The choice of the surgical procedure was at the surgeon's discretion. In all cases, the entire mesorectum was removed. Specimens were inked for lateral margin determination. R1 resection was defined as lateral clearance less than one $\mathrm{mm}$.

Clinical, operative, and histopathological data were recorded prospectively in a computerized registry database including patient age, gender, tumor site, tumor stage according to UICC stage [8], histological differentiation, gross morphology, tumor size, local invasion, nodal status and type of surgery.

\section{Follow-up}

All patients were seen on regular follow-up including clinical history, physical examination, laboratory investigations, abdominal ultrasonography, chest X-ray, and endoscopy (sigmoidoscopy after 6 months, total colonoscopy after one year). They were followed semi-annually during the period of 2-5 years postoperatively until death or the closing date of the study (July 2004). Any regrowth of tumor within the pelvis was considered as a local recurrence. The diagnosis of a pelvic recurrence was preferably proven by histology and/or cytology; however, in the majority of cases, the diagnosis was made on clinical or radiological grounds. Data collected were entered prospectively into the registry database. Median follow-up of all patients was 36 months (range: 6-86 months).

\section{Statistical methods}

The characteristics of EGFR staining were examined for correlation with tumor- and patient-related prognostic factors. The cut-off of $25 \%$ of EGFR staining corresponded to the third quartile of EGFR extent and was then selected for all statistical correlations. Categorical variables were reported by means of contingency tables. Furthermore, for continuous variables the median and range were computed.

To investigate the association between trial features, univariate statistical analyses were performed using Pearson's Chi-2 test or Fisher's exact test when applicable.

Survival times to all events were measured from the day of surgery to the time of the event or to last news if no event occurred. Relapse-free survival (RFS; event was all relapse), locoregional recurrence-free survival (LRFS; event was locoregional recurrence), and distant metastasis-free survival (MFS; event was distant metastasis relapse) rates were estimated according to the KaplanMeier method. Patients not presenting the event of interest were considered censored at the last known follow up of time. Survival curves were drawn, and the logrank test was performed to assess differences between the groups.
Cox's proportional hazards regression using a stepwise selection procedure was used to investigate prognostic factors. Hazards ratios with $95 \%$ confidence interval, CI, are presented.

All P values reported were two-sided, and differences were considered as significant at the $5 \%$ level. Data were analyzed with software STATA 7.0 (Stata Corporation, College Station, TX, USA).

\section{Results \\ EGFR expression}

The semi-quantitative analysis of EGFR expression is summarized in Table 1. Fifty-six percent of the cases demonstrated EGFR expression, and 44\% had negative staining. EGFR staining extent superior to $25 \%$ was observed in $26 \%$ of the cases, and the staining intensity was graded as strong in $8 \%$. Strong staining intensity occurred statistically more frequently in those cases with EGFR extent $\geq 25 \%$ than in those with $<25 \%(P=0.018)$.

EGFR and clinical characteristics of the study population A total of 77 patients were evaluable for EGFR expression. Median age was 64 years (range: 30-88). Twenty-six (34\%) were female and 19 (25\%) were staged as stage III patients. A majority of patients presented T3/T4 (72\%) rectal tumor. Initial tumor was located in the lower third ( $\mathrm{n}=52,68 \%)$, middle third $(\mathrm{n}=17,22 \%)$, and upper third ( $\mathrm{n}=8,10 \%)$ of the rectum. Twenty-five patients $(32 \%)$ received a total radiation dose of $60 \mathrm{~Gy}$ for a sphincter-conserving approach. Thirteen patients (17\%) and 25 patients (32\%) received preoperative concomitant chemo-radiotherapy and adjuvant chemotherapy, respectively. Microscopic incomplete surgery (R1) was achieved in 7 patients $(9 \%)$, and all corresponded to initially T4 tumors.

We compared the distribution of patients and tumor characteristics and treatment according to EGFR expression (staining intensity and extent) to assess the presence of potential imbalances in the known prognostic variables. Table 2 shows no significant differences between the groups in the distribution of known clinical prognostic indicators of loco-regional control and survival, i.e., age, gender, stage group, tumor location, preoperative total dose RT, concomitant chemo-radiotherapy, type of surgery, resection margins. Neither was any imbalance observed for patients who received adjuvant chemotherapy.

\section{EGFR expression and relapse}

Overall tumor progression, caused by local recurrence alone $(\mathrm{n}=1,1.3 \%)$, distant metastases alone $(\mathrm{n}=8$, $10.4 \%)$, and both of them $(n=7,9.1 \%)$ occurred in 16 patients $(20.8 \%)$. 
Table I: EGFR immunohistochemical staining characteristics in rectal-cancer patients

\begin{tabular}{|c|c|c|c|c|c|}
\hline EGFR staining & Patientsa ${ }^{\mathrm{a}}(\%)$ & EGFR extent & Patients $^{\mathrm{a}}(\%)$ & EGFR intensity & Patients $^{\mathrm{a}}(\%)$ \\
\hline Negative & $34(44)$ & - & - & - & - \\
\hline \multirow[t]{4}{*}{ Positive } & $43(56)$ & $<25 \%$ & $23(30)$ & Weak and moderate & $21(27)$ \\
\hline & & & & Strong & $2(3)$ \\
\hline & & $\geq 25 \%$ & $20(26)$ & Weak and moderate & $16(21)$ \\
\hline & & & & Strong & $4(5)$ \\
\hline
\end{tabular}

aNumber of patients

Table 2: EGFR expression and clinical characteristics of the study population

\begin{tabular}{|c|c|c|c|c|c|c|c|}
\hline \multirow[b]{2}{*}{ Parameters } & \multicolumn{2}{|c|}{ EGFR extent } & \multirow[t]{2}{*}{$P$ value } & \multicolumn{3}{|c|}{ EGFR intensity } & \multirow[t]{2}{*}{$P$ value } \\
\hline & $<25 \%$ & $\geq 25 \%$ & & Negative to moderate & Strong & & \\
\hline \multicolumn{8}{|l|}{ Age $(y)$} \\
\hline$\leq 64$ & $26(45.6)^{\mathrm{a}}$ & $13(65)$ & & $36(50.7)$ & $3(50)$ & & \\
\hline$>64$ & $31(54.4)$ & $7(35)$ & 0.14 & $35(49.3)$ & $3(50)$ & & 0.97 \\
\hline \multicolumn{8}{|l|}{ Gender } \\
\hline Male & $38(66.7)$ & $13(65)$ & & $47(66.2)$ & $4(66.7)$ & & \\
\hline Female & $19(33.3)$ & $7(35)$ & 0.89 & $24(33.8)$ & $2(33.3)$ & & 0.98 \\
\hline \multicolumn{8}{|l|}{ Stage group ${ }^{b}$} \\
\hline II & $43(75.4)$ & $15(75)$ & & $54(76.1)$ & $4(66.7)$ & & \\
\hline III & $14(24.6)$ & $5(25)$ & 0.97 & $17(23.9)$ & $2(33.3)$ & & 0.61 \\
\hline \multicolumn{8}{|l|}{ Tumor location } \\
\hline Lower third & $39(68.4)$ & $13(65)$ & & $46(64.8)$ & $6(100)$ & & \\
\hline Middle third & $12(21.1)$ & $5(25)$ & & $17(23.9)$ & & - & \\
\hline Upper third & $6(10.5)$ & $2(10)$ & 0.96 & $8(11.3)$ & & - & 0.21 \\
\hline \multicolumn{8}{|l|}{ Preoperative } \\
\hline RT-CTc & $8(14)$ & $5(25)$ & 0.26 & II (I5.5) & $2(33.3)$ & & 0.26 \\
\hline \multicolumn{8}{|l|}{ Preoperative RT } \\
\hline $44 \mathrm{~Gy}$ & $40(70.2)$ & $12(60)$ & & $48(67.6)$ & $4(66.7)$ & & \\
\hline $60 \mathrm{~Gy}$ & $17(28.8)$ & $8(40)$ & 0.40 & $23(32.4)$ & $2(33.3)$ & & 0.96 \\
\hline \multicolumn{8}{|l|}{ Type of surgeryd } \\
\hline AP & $46(80.7)$ & $17(85)$ & & $58(81.7)$ & $5(83.3)$ & & \\
\hline LAR & II (19.3) & $3(15)$ & 0.67 & $13(18.3)$ & I (16.7) & & 0.92 \\
\hline \multicolumn{8}{|l|}{ Resection } \\
\hline \multicolumn{8}{|l|}{ Margins } \\
\hline - & $52(93)$ & $17(85)$ & & $63(90)$ & $6(100)$ & & \\
\hline+ & $4(7)$ & $3(15)$ & 0.30 & $7(10)$ & & - & 0.41 \\
\hline \multicolumn{8}{|l|}{ Adjuvant } \\
\hline chemotherapy & $16(28.1)$ & $9(45)$ & 0.16 & $24(33.8)$ & I (16.7) & & 0.39 \\
\hline
\end{tabular}

aData are presented as number of patients, with the percentage in parentheses.

bAccording to AJCC (American Joint Committee on Cancer) 1997.

cPreoperative chemo-radiotherapy.

dAP, abdominoperineal excision; LAR, low anterior resection

Patients with EGFR extent $\geq 25 \%$ had a higher locoregional recurrence rate $(20 \%$ vs $7 \%$ ). The two-year LRFS rate was $94 \%(92-98 \%)$ in patients with EGFR extent $<25 \%$ and $84 \%(58-95 \%)$ in patients with EGFR extent $\geq 25 \%$ with a borderline statistical difference $(P=0.06$, Figure 2).
An EGFR extent of $\geq 25 \%$ was associated with poorer MFS (84\% [59-95\%] vs 95\% [84-98\%]) but the difference did not achieve statistical significance. Metastatic evolution corresponded to lung, liver, peritoneum, bone, and brain in $60 \%, 40 \%, 26 \%, 13 \%$ and $7 \%$, respectively. No differ- 


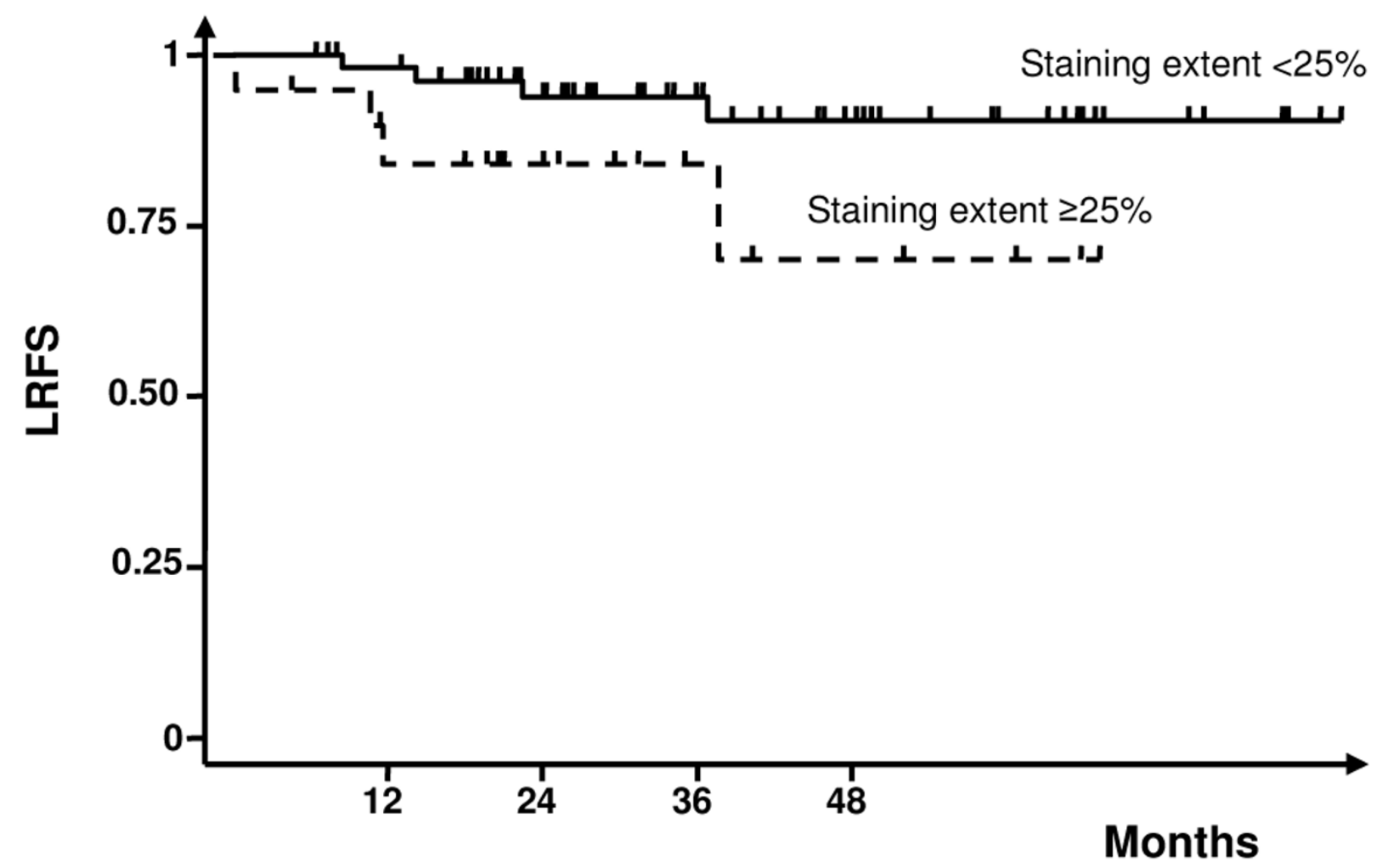

Figure 2

Locoregional recurrence-free survival curves according to epidermal growth factor receptor (EGFR) expression extent.

ence was observed in the pattern of metastatic failure according to EGFR status.

Patients with strong EGFR staining intensity had a higher loco-regional recurrence rate $(17 \%$ vs $10 \%)$ and a poorer RFS than those with negative to moderate staining intensity but without significant statistical difference.

Univariate analysis did not show any significant association of tumor local recurrence with age $(P=0.48)$, gender $(\mathrm{P}=0.81)$, UICC stage III $(\mathrm{P}=0.08)$, tumor location $(\mathrm{P}=$ $0.60)$, preoperative chemotherapy $(P=0.73)$, preoperative RT $(P=0.26)$, type of surgery $(P=0.66)$, resection margins $(\mathrm{P}=0.10)$, and adjuvant chemotherapy $(\mathrm{P}=$ $0.75)$. To adjust for prognostic factors, the clinical parameters described in Table 2 were included in the multivariate analysis using the Cox proportional hazards model, i.e., EGFR extent ( $<25 \%$ vs $\geq 25 \%$ ), resection (complete [R0] vs R1), tumor stage (II vs III), preoperative total dose RT (44 vs $60 \mathrm{Gy),} \mathrm{gender,} \mathrm{tumor} \mathrm{location} \mathrm{(lower} \mathrm{third} \mathrm{vs}$ other thirds), type of surgery, resection margins, age $(\leq 64$ vs >64 years old), preoperative concomitant chemo-radiotherapy (no vs yes), EGFR intensity (negative to moderate vs strong), delay from the last day of RT to the day of surgery ( $\leq 41$ vs $>41$ days) and $\mathrm{uT}$.

EGFR extent expression, R1 resection, and 44-Gy total dose radiation were the independent prognostic factors that predicted locoregional failure with $P$ values of 0.037 , 0.032 , and 0.045 , respectively (Table 3 ). For both RFS and MFS, stage III tumor was detected as an independent prognostic factor with $\mathrm{P}$ values of 0.024 (hazard ratio $=4.08$, CI 95\%, 1.21-13.82) and 0.023 (hazard ratio = 4, CI 95\%, 1.22-13.13), respectively. Concomitant preoperative chemo-radiotherapy was detected as a potential prognostic factor for RFS and MFS but statistical analysis showed only a trend towards significance $P=0.057$ and 0.070 , respectively. Margin resection $<1 \mathrm{~mm}$ was also detected as a significant prognostic factor for MFS (hazard ratio = 5.03, CI 95\%, 1.02-24.78, P = 0.047). EGFR expression predicted neither RFS (hazard ratio $=1.11$, CI 95\%, 0.28- 
Table 3: Cox multivariate regression analysis for loco-regional recurrence-free survival (LRFS) ${ }^{\mathrm{a}}$

\begin{tabular}{|c|c|c|c|c|}
\hline Prognostic variable & & Hazard ratio & $95 \% \mathrm{Cl}^{\mathrm{b}}$ & Pvalue \\
\hline EGFR extent & $\begin{array}{l}<25 \% \\
\geq 25 \%\end{array}$ & $\begin{array}{c}1 \\
7.18\end{array}$ & 1.12 to 46 & 0.037 \\
\hline Resection & $\begin{array}{l}\text { Ro } \\
\text { RI }\end{array}$ & $\begin{array}{c}1 \\
6.92\end{array}$ & 1.18 to 40.42 & 0.032 \\
\hline Preoperative RT & $\begin{array}{l}60 \mathrm{~Gy} \\
44 \mathrm{~Gy}\end{array}$ & $\begin{array}{c}1 \\
5.78\end{array}$ & 1.04 to 32.06 & 0.045 \\
\hline
\end{tabular}

aResults were adjusted on tumor stage, gender, type of surgery, surgical margin, age, preoperative radio-chemotherapy, EGFR intensity, delay from radiotherapy to surgery, and $\mathrm{uT}$

${ }^{b} \mathrm{Cl}$, confidence interval

4.46, $\mathrm{P}=0.88$ ) nor OS (hazard ratio $=1.26, \mathrm{CI} 95 \%, 0.30-$ 5.41, $\mathrm{P}=0.753)$.

\section{Discussion}

The identification of parameters that reflect biological behavior of individual cancer tissues correlating with tumor aggressiveness is a key determinant of prognosis and a fundamental issue for the improvement of cancer therapy. Despite recent progress in defining the molecular mechanisms of cancer development and tumor progression, only a few individual biomarkers providing prognostic information have been identified. Among them, the EGFR pathways attracted the most attention of cancer investigators.

EGFR (HER1), a transmembrane glycoprotein, is a member of the large receptor tyrosine family encoded by a gene located in human chromosome 7p12. EGFR exists in inactive monomer form or in active dimer form. Dimerization can take place between different receptors in order to develop homologue (homodimers) or heterologue (heterodimers) dimers [9]. In either normal or malignant cells, the activation of EGF receptor cascades may have multiple consequences such as cell growth, differentiation, and proliferation. EGF receptor cascades may also promote malignant transformation, angiogenesis, and/or metastatic dissemination $[10,11]$.

In addition, the cell membrane has been known for some time to be a secondary target for ionizing radiation. This phenomenon may provoke the pathways of mitogen-activated protein kinase (MAPK), phosphatidyl inositol-3phosphate kinase (PI3K), and MAPK8 activation [12], which can modulate cell proliferation or death. Preclinical and clinical studies associate EGFR expression with radioresistance [13-16]. Ionizing radiation produces several types of cellular response via activation of multiple transduction pathways resulting in cell death, differentiation, or proliferation. Following irradiation, the MAPK path- way was recently reported to be a cellular "SOS" signal initiator starting from EGF receptors [17]. MAPK pathway activation via EGFR receptors was reported in many malignant human cell lines [17-19]. This activation is similar to the one produced by physiological concentrations of EGF ( $0.1 \mathrm{nM})$, and seems to act as a radioprotector $[16,17,19,20]$. Moreover, it has been recently shown that EGF-receptor and MAPK signal pathway activation following ionizing radiation depends on the proteolytic clivage of TGF $\beta$ precursor and functional activation of autocrine TGF $\beta$ [21]. STAT-3 signal pathway activation by phosphorylation via EGF receptors can be initiated by ionizing radiation, and it results with a radioprotective effect by apoptosis inhibition [22-24]. An inverse relation between the number of EGF receptors and tumor radiocurability is reported in several murine cell lines. In these models, radiation-induced apoptosis was decreased when important levels of EGF receptor were expressed on the cells $[25,26]$. Clinical consequences of these findings would be tailoring treatment according to a simple predictive assay of radiosensitivity based on the EGF-receptor expression. Clinical data pertaining to the relationship between EGFR expression and the success of radiotherapy are sparse and equivocal. Nevertheless, with respect to squamous-cell cancer of the head and neck, EGFR is among the best-studied examples [27-33], and positive and negative correlations between EGFR levels and tumor recurrences were reported in laryngeal cancers after radiotherapy [34-36]. The relationship of EGFR levels to the prognosis in unresectable pharyngeal or nasopharyngeal cancer patients treated by chemo-radiotherapy was recently reported [37-39].

In colorectal cancer, EGFR expression was evaluated in resected tumors [40]. The authors found significantly higher EGFR levels in stage III cancers than in stages I and II. It was then concluded that high EGFR expression is associated with poor prognosis. Another group [41], found 72 cases of EGFR-positive expression in 82 resected 
colorectal adenocarcinomas (88\%). The extent of EGFR expression $(>50 \%$ ) revealed significant differences in survival times. In our study, a significant correlation between the positive tumor cell percentage greater than $25 \%$ and the rate of locoregional recurrence was detected $(\mathrm{P}=$ $0.037)$.

We did not assess the predictive value of EGFR on tumor response after preoperative treatment. This question was recently tackled by Giralt et al [42]. The authors analyzed EGFR expression of 45 locally advanced-rectal-cancer patients treated with preoperative radiotherapy and total mesorectal resection. Immunochemistry for EGFR was determined at the preradiation diagnostic biopsy and in the resected specimens. EGFR positivity was observed in 29 of 45 tumors (64\%) and was associated with neither clinical tumor stage nor clinical nodal stage. The overall response rate was 34\% in EGFR positive patients vs. $62 \%$ in those who did not express EGFR $(P=0.07)$. Only one of the seven pathologic complete remission patients was EGFR positive $(P=0.003)$. The link between the positive EGFR expression and the microscopic response on surgical specimen seems to be logical, but we fail to assess it in our series. Such a relationship should be based on a large tumor sampling and needs a very strict procedure at the macroscopic level, to ensure that the whole tumor is analyzed after a neoadjuvant treatment. An exhaustive tissue material should allow a precise analysis of the entire spectrum of tumor regression, i.e., complete, partial or none, as it has been proposed by Dvorack et al [43]. It should then be of interest to correlate these well documented histopathological data with biological parameters such as EGFR.

In our study EGFR expression was not found to be an independent prognostic factor for overall survival in patients with rectal cancer. Other studies, described above $[40,41]$, have reported variable results making it difficult to draw firm conclusions about a possible relationship between EGFR expression and overall survival. Probably, the variation in results is due to (i) the use of different laboratory tests, (ii) varying extent of follow-up, and (iii) heterogeneity in the population of colon- and rectum-cancer patients. (i) EGFR assessment in previous studies was obtained by using different antibodies, different methods of antigen retrieval, and different cut-off values. In this study, we used uniform reagents provided by a kit allowing minimized variations in results and a reproducible method. Therefore, our results detected a low percentage of EGFR immunopositivity (56\%) as compared with other colorectal cancer trials [44] probably due to the numerous IHC techniques. (ii) In this study we did not have a sufficiently long follow-up to give definitive conclusions on the prognostic impact on EGFR expression and overall survival. In fact, our analysis was only based on a group of patients with rectal carcinoma, a disease with a natural history different from that of colon carcinoma especially with respect to the tendency to recur locally. (iii) Reasons for recurrence after curative resection for colorectal carcinoma are not completely clear. Several theories have been put forward including, amongst others, microscopic deposits in the lymphatics, inadequate distant and lateral resection margins, exfoliated tumor cells at time of surgery, presence of malignant cells in the anastomosis and, finally, tumor aggressiveness related to biological behaviour. It is known that reported recurrence after resection for rectal carcinoma is commonly higher than after colon carcinoma $[45,46]$, and differences in prognosis have also been reported between high and low rectal carcinomas [47]. Risk factors that have previously been associated with increased recurrence rates include amongst others patient age, gender, tumor stage, site of lesion (colon vs rectum), infiltration of adjacent organs, histopathological criteria, tumor size, lymph-node involvement and radial resection margins $[45,46,48-50]$. In rectal cancer, in particular, the impact of surgery and adequate lymph-node dissection related to the risk of local recurrence have been highlighted [51]. Several studies have evaluated the prognostic significance of EGFR on survival in colorectal cancer but, to our knowledge, not specifically focusing on rectal cancer recurrence.

In our study, multivariate statistical model identified EGFR expression as a significant independent predictor of recurrence following preoperative and curative surgery for rectal cancer. Two possible explanations for this relationship are to be considered. Firstly, EGFR overexpressing tumors exhibit a more aggressive behavior leading to more pelvic recurrences and in a lesser extent to more distant metastases. A second possible explanation is that EGFR overexpressing tumors present decreased intrinsic radiosensitivity as explained at the first part of this discussion and lead to more pelvic recurrences. This explanation is supported by the fact that the majority of the observed recurrences in our study appeared in the irradiated areas.

Therapeutic approaches targeting EGFR signaling pathways either alone or in combination with radiation or cytotoxic agents are being intensively investigated [52]. Strategies that are in various stages of development include blockade of the extracellular receptor domain [44] and inhibition of the intracellular tyrosine kinase activity [53]. Data presented in Figure 2 suggest that tumor radiation-sensitization through the inhibition of EGFR signaling could yield a therapeutic gain by increasing the locoregional control rate in patients with EGFR-overexpressing rectal cancer. 


\section{Conclusion}

Knowledge of expression of EGFR in rectal cancer can contribute to the identification of patients with an increased risk of recurrences. Our results have to be related to several confounding factors such as the small number of events and the retrospective approach. Nevertheless, the potential of introducing routine EGFR immunohistochemistry as a diagnostic tool into the clinical practice of rectal cancer management still has to be undertaken, and may allow clinicians to deliver targeted therapies even in patients with a poorer prognosis.

\section{Competing interests}

The author(s) declare that they have no competing interests.

\section{Authors' contributions}

DA conceived the study, participated in its design and coordination. FB performed all EGFR immunohistochemical analyses. NB made acquisition of the data. AZ, MO, $\mathrm{MY}, \mathrm{CL}, \mathrm{PR}, \mathrm{AP}$, and JBD participated in the design of the study, in its analysis and in the interpretation of the data. DA, FB, ST, and MO drafted the manuscript. ST performed all statistical analyses. All authors read and approved the final manuscript.

\section{Acknowledgements}

The authors thank Ms Lavaill for excellent technical assistance, and Ms. Frances Godson for excellent editorial assistance.

\section{References}

I. Kane JM, Petrelli NJ: Controversies in the surgical management of rectal cancer. Semin Radiat Oncol 2003, 13:403-418.

2. Kapiteijn E, Marijnen CA, Nagtegaal ID, Putter H, Steup WH, Wiggers T, Rutten HJ, Pahlman L, Glimelius B, van Krieken JH, Leer JW, van de Velde CJ: Preoperative radiotherapy combined with total mesorectal excision for resectable rectal cancer. N EnglJ Med 200I, 345:638-646.

3. Colorectal Cancer Collaborative Group: Adjuvant radiotherapy for rectal cancer: a systematic overview of 8,507 patients from 22 randomised trials. Lancet 200I, 358:|29|-I304.

4. Wiggenraad R, Tamminga R, Blok P, Rouse R, Hermans J: The prognostic significance of p53 expression for survival and local control in rectal carcinoma treated with surgery and postoperative radiotherapy. Int J Radiat Oncol Biol Phys 1998, 41:29-35.

5. Lopez-Crapez E, Ychou M, Thèzenas S, Simony-Lafontaine J, Thirion A, Azria D, Bibeau F, Grenier J, Senesse P: P53 status and response to radiotherapy in rectal cancer : a prospective multilevel analysis. B J Cancer 2005, 92( I 2):2 I |4-2 I2I.

6. Tannapfel A, Nusslein S, Fietkau R, Katalinic A, Kockerling F, Wittekind C: Apoptosis, proliferation, bax, bcl-2 and p53 status prior to and after preoperative radiochemotherapy for locally advanced rectal cancer. Int J Radiat Oncol Biol Phys 1998, 4I:585-591.

7. International Commission on Radiation Units and Measurements (ICRU): Prescribing, recording, and reporting photon beam therapy. ICRU report 62. Bethesda, Maryland; 200I.

8. Sobin L, Wittekind C, UICC eds: TNM Classification of Malignant Tumours. New York: Wiley-Liss; 1997.

9. Alroy I, Yarden Y: The ErbB signaling network in embryogenesis and oncogenesis: signal diversification through combinatorial ligand-receptor interactions. FEBS Lett 1997, 41 0:83-86.

10. Hudziak RM, Schlessinger J, Ullrich A: Increased expression of the putative growth factor receptor p I85HER2 causes transfor- mation and tumorigenesis of NIH 3 T3 cells. Proc Natl Acad Sci U S A 1987, 84:7159-7|63.

II. Allred DC, Clark GM, Molina R, Tandon AK, Schnitt SJ, Gilchrist KW, Osborne CK, Tormey DC, McGuire WL: Overexpression of HER$2 /$ neu and its relationship with other prognostic factors change during the progression of in situ to invasive breast cancer. Hum Pathol 1992, 23:974-979.

12. Schmidt-Ullrich RK, Dent P, Grant S, Mikkelsen RB, Valerie K: Signal transduction and cellular radiation responses. Radiat $R e s 2000$, 153:245-257.

13. Wollman R, Yahalom J, Maxy R, Pinto J, Fuks Z: Effect of epidermal growth factor on the growth and radiation sensitivity of human breast cancer cells in vitro. Int J Radiat Oncol Biol Phys 1994, 30:91-98.

14. Gupta AK, McKenna WG, Weber CN, Feldman MD, Goldsmith JD, Mick R, Machtay M, Rosenthal DI, Bakanauskas VJ, Cerniglia GJ, Bernhard EJ, Weber RS, Muschel RJ: Local recurrence in head and neck cancer: relationship to radiation resistance and signal transduction. Clin Cancer Res 2002, 8:885-892.

15. Barker FG, Simmons ML, Chang SM, Prados MD, Larson DA, Sneed PK, Wara WM, Berger MS, Chen P, Israel MA, Aldape KD: EGFR overexpression and radiation response in glioblastoma multiforme. Int J Radiat Oncol Biol Phys 200I, 5I:410-4I8.

16. Balaban N, Moni J, Shannon M, Dang L, Murphy E, Goldkorn T: The effect of ionizing radiation on signal transduction: antibodies to EGF receptor sensitize A43 I cells to radiation. Biochim Biophys Acta 1996, I 3 I 4: I 47-I56.

17. Schmidt-Ullrich RK, Mikkelsen RB, Dent P, Todd DG, Valerie K, Kavanagh BD, Contessa JN, Rorrer WK, Chen PB: Radiationinduced proliferation of the human A43I squamous carcinoma cells is dependent on EGFR tyrosine phosphorylation. Oncogene 1997, 15:1191-1197.

18. Carter S, Auer KL, Reardon DB, Birrer M, Fisher PB, Valerie K, Schmidt-Ullrich R, Mikkelsen R, Dent P: Inhibition of the mitogen activated protein (MAP) kinase cascade potentiates cell killing by low dose ionizing radiation in A43I human squamous carcinoma cells. Oncogene 1998, 16:2787-2796.

19. Kavanagh BD, Dent P, Schmidt-Ullrich RK, Chen P, Mikkelsen RB: Calcium-dependent stimulation of mitogen-activated protein kinase activity in A43 I cells by low doses of ionizing radiation. Radiat Res 1998, 149:579-587.

20. Goldkorn T, Balaban N, Shannon M, Matsukuma K: EGF receptor phosphorylation is affected by ionizing radiation. Biochim Biophys Acta 1997, 1358:289-299.

21. Dent P, Reardon DB, Park JS, Bowers G, Logsdon C, Valerie K, Schmidt-Ullrich R: Radiation-induced release of transforming growth factor alpha activates the epidermal growth factor receptor and mitogen-activated protein kinase pathway in carcinoma cells, leading to increased proliferation and protection from radiation-induced cell death. Mol Biol Cell 1999, 10:2493-2506.

22. David M, Wong L, Flavell R, Thompson SA, Wells A, Larner AC, Johnson GR: STAT activation by epidermal growth factor (EGF) and amphiregulin. Requirement for the EGF receptor kinase but not for tyrosine phosphorylation sites or JAKI. J Biol Chem 1996, $271: 9185-9188$.

23. Grandis JR, Drenning SD, Zeng Q, Watkins SC, Melhem MF, Endo S, Johnson DE, Huang L, He Y, Kim JD: Constitutive activation of Stat3 signaling abrogates apoptosis in squamous cell carcinogenesis in vivo. Proc Natl Acad Sci U S A 2000, 97:4227-4232.

24. Park OK, Schaefer TS, Nathans D: In vitro activation of Stat3 by epidermal growth factor receptor kinase. Proc Natl Acad Sci U SA 1996, 93:13704-13708.

25. Akimoto T, Hunter NR, Buchmiller L, Mason K, Kian Ang K, Milas L: Inverse relationship between epidermal growth factor receptor expression and radiocurability of murine carcinomas. Clin Cancer Res 1999, 5:2884-2890.

26. Sheridan MT, O'Dwyer T, Seymour CB, Mothersill CE: Potential indicators of radiosensitivity in squamous cell carcinoma of the head and neck. Radiat Oncol Investig 1997, 5:180-186.

27. Christensen ME, Therkildsen MH, Poulsen SS, Bretlau P: Immunoreactive transforming growth factor alpha and epidermal growth factor in oral squamous cell carcinomas. J Pathol 1993, 169:323-328.

28. Dassonville O, Formento JL, Francoual M, Ramaioli A, Santini J, Schneider M, Demard F, Milano G: Expression of epidermal growth 
factor receptor and survival in upper aerodigestive tract cancer. J Clin Oncol 1993, I I:1873-1878.

29. Grandis JR, Tweardy DJ: TGF-alpha and EGFR in head and neck cancer. J Cell Biochem 1993, I7F(Suppl):|88-| |9|.

30. Lee CS, Redshaw A, Boag G: Epidermal growth factor receptor immunoreactivity in human laryngeal squamous cell carcinoma. Pathology 1997, 29:25I-254.

31. Maiorano E, Favia G, Maisonneuve P, Viale G: Prognostic implications of epidermal growth factor receptor immunoreactivity in squamous cell carcinoma of the oral mucosa. J Pathol 1998, 185:167-174.

32. Santini J, Formento JL, Francoual M, Milano G, Schneider M, Dassonville O, Demard F: Characterization, quantification, and potential clinical value of the epidermal growth factor receptor in head and neck squamous cell carcinomas. Head Neck 199|, 13:132-139.

33. Etienne MC, Pivot $X$, Formento JL, Bensadoun RJ, Formento $P$, Dassonville $O$, Francoual M, Poissonnet G, Fontana X, Schneider M, Demard F, Milano G: A multifactorial approach including tumoural epidermal growth factor receptor, p53, thymidylate synthase and dihydropyrimidine dehydrogenase to predict treatment outcome in head and neck cancer patients receiving 5-fluorouracil. $\mathrm{Br}$ J Cancer 1999, 79:1864-1869.

34. Miyaguchi M, Olofsson J, Hellquist HB: Expression of epidermal growth factor receptor in glottic carcinoma and its relation to recurrence after radiotherapy. Clin Otolaryngol 1991, 16:466-469.

35. Wen QH, Miwa T, Yoshizaki T, Nagayama I, Furukawa M, Nishijima $\mathrm{H}$ : Prognostic value of EGFR and TGF-alpha in early laryngeal cancer treated with radiotherapy. Laryngoscope 1996, 106:884-888.

36. Almadori G, Cadoni G, Galli J, Ferrandina G, Scambia G, Exarchakos G, Paludetti G, Ottaviani F: Epidermal growth factor receptor expression in primary laryngeal cancer: an independent prognostic factor of neck node relapse. Int J Cancer 1999, 84: $|88-| 9 \mid$.

37. Ang KK, Berkey BA, Tu X, Zhang HZ, Katz R, Hammond EH, Fu KK, Milas L: Impact of epidermal growth factor receptor expression on survival and pattern of relapse in patients with advanced head and neck carcinoma. Cancer Res 2002, 62:7350-7356.

38. Magne N, Pivot X, Bensadoun RJ, Guardiola E, Poissonnet G, Dassonville O, Francoual M, Formento JL, Demard F, Schneider M, Milano G: The relationship of epidermal growth factor receptor levels to the prognosis of unresectable pharyngeal cancer patients treated by chemo- radiotherapy. Eur J Cancer 200I, 37:2169-2177.

39. Chua DT, Nicholls JM, Sham JS, Au GK: Prognostic value of epidermal growth factor receptor expression in patients with advanced stage nasopharyngeal carcinoma treated with induction chemotherapy and radiotherapy. Int J Radiat Oncol Biol Phys 2004, 59: I I-20.

40. Steele RJ, Kelly P, Ellul B, Eremin O: Epidermal growth factor receptor expression in colorectal cancer. Br J Surg 1990, 77:1352-1354

4I. Mayer A, Takimoto M, Fritz E, Schellander G, Kofler K, Ludwig H: The prognostic significance of proliferating cell nuclear antigen, epidermal growth factor receptor, and $\mathrm{mdr}$ gene expression in colorectal cancer. Cancer 1993, 71:2454-2460.

42. Giralt J, Eraso A, Armengol M, Rossello J, Majo J, Ares C, Espin E, Benavente $S$, de Torres I: Epidermal growth factor receptor is a predictor of tumor response in locally advanced rectal cancer patients treated with preoperative radiotherapy. Int J Radiat Oncol Biol Phys 2002, 54:1460-1465.

43. Dworak O, Keilholz L, Hoffmann A: Pathological features of rectal cancer after preoperative radiochemotherapy. Int J Colorectal Dis 1997, 12:19-23.

44. Cunningham $D$, Humblet $Y$, Siena $S$, Khayat $D$, Bleiberg $H$, Santoro $A$, Bets D, Mueser M, Harstrick A, Verslype C, Chau I, van Custem E: Cetuximab monotherapy and cetuximab plus irinotecan in irinotecan-refractory metastatic colorectal cancer. N Engl J Med 2004, 35 I:337-345.

45. Galandiuk S, Wieand HS, Moertel CG, Cha SS, Fitzgibbons RJ, Pemberton JH, Wolff BG: Patterns of recurrence after curative resection of carcinoma of the colon and rectum. Surg Gynecol Obstet 1992, I74:27-32.

46. Obrand $\mathrm{DI}$, Gordon PH: Incidence and patterns of recurrence following curative resection for colorectal carcinoma. Dis Colon Rectum 1997, 40:15-24.

47. Konn M, Morita T, Hada R, Yamanaka Y, Sasaki M, Munakata H, Suzuki $H$, Inoue $S$, Endoh M, Sugiyama $Y$ : Survival and recurrence after low anterior resection and abdominoperineal resection for rectal cancer: the results of a long-term study with a review of the literature. Surg Today 1993, 23:21-30.

48. Michelassi F, Vannucci L, Ayala JJ, Chappel R, Goldberg R, Block GE: Local recurrence after curative resection of colorectal adenocarcinoma. Surgery 1990, 108:787-792.

49. Arbman G, Nilsson E, Hallbook O, Sjodahl R: Local recurrence following total mesorectal excision for rectal cancer. Br J Surg 1996, 83:375-379.

50. de Haas-Kock DF, Baeten CG, Jager JJ, Langendijk JA, Schouten LJ, Volovics A, Arends JW: Prognostic significance of radial margins of clearance in rectal cancer. Br J Surg 1996, 83:78I-785.

5I. Bjerkeset T, Edna TH: Rectal cancer: the influence of type of operation on local recurrence and survival. Eur J Surg 1996, 162:643-648.

52. Azria $D$, Larbouret $C$, Robert $B$, Culine $S$, Ychou M, Verrelle $P$, Dubois JB, Pelegrin A: Anti-EGF receptors and radiation therapy: current translational research and early clinical trials. Bull Cancer 2003, 90:202-2I2.

53. Sartor $\mathrm{Cl}$ : Epidermal growth factor family receptors and inhibitors: radiation response modulators. Semin Radiat Oncol 2003, I3:22-30.

\section{Pre-publication history}

The pre-publication history for this paper can be accessed here:

http://www.biomedcentral.com/1471-2407/5/62/prepub

Publish with Biomed Central and every scientist can read your work free of charge

"BioMed Central will be the most significant development for disseminating the results of biomedical research in our lifetime. "

Sir Paul Nurse, Cancer Research UK

Your research papers will be:

- available free of charge to the entire biomedical community

- peer reviewed and published immediately upon acceptance

- cited in PubMed and archived on PubMed Central

- yours - you keep the copyright 